АНАЛИЗ ПРЕДВСПЫШЕЧНОЙ ФАЗЫ ЭРУПТИВНЫХ И НЕЭРУПТИВНЫХ ВСПЫШЕК ПО ДАННЫМ О ПРОСТРАНСТВЕННОЙ ДИНАМИКЕ КОРОНАЛЬНЫХ МАГНИТНЫХ СТРУКТУР И ИХ МИКРОВОЛНОВОГО И УЛЬТРАФИОЛЕТОВОГО ИЗЛУЧЕНИЙ

\author{
Бакунина И.А. ${ }^{1}$, Мельников В.Ф. ${ }^{2}$, Шаин А.В. ${ }^{2}$, \\ Абрамов-Максимов B.E. ${ }^{2}$, Моргачев А.C. ${ }^{3}$ \\ ${ }^{1}$ Национальный исследовательский университет «Высшая школа экономики», \\ Нижний Новгород, Россия \\ ${ }^{2}$ Главная (Пулковская) астрономическая обсерватория РАН, Санкт-Петербург, Россия \\ ${ }^{3}$ Нижегородский государственный университет им. Н.И. Лобачевского, \\ Нижний Новгород, Россия
}

\title{
ANALYSIS OF THE PRE-FLARE PHASE OF ERUPTIVE AND NON-ERUPTIVE FLARES ACCORDING TO THE DATA ON SPATIAL DYNAMICS OF CORONAL MAGNETIC STRUCTURES AND THEIR MICROWAVE AND ULTRAVIOLET EMISSION
}

\author{
Bakunina I.A. ${ }^{1}$, Melnikov V.F. ${ }^{2}$, Shain A.V. ${ }^{2}$, \\ Abramov-Maximov V.E. ${ }^{2}$, Morgachev A.S. ${ }^{3}$ \\ ${ }^{1}$ National Research University Higher School of Economics, Nizhny Novgorod, Russia \\ ${ }^{2}$ Pulkovo Observatory, St. Petersburg, Russia \\ ${ }^{3}$ Lobachevsky State University, Nizhniy Novgorod, Russia
}

The dynamics of microwave and EUV emission is considered for active regions with CME and with no eruption. Extrapolation of the magnetic field to the corona of active region (AR) has shown that an eruption event may be connected with the presence of a twisted magnetic field and an open magnetic configuration in the flare site of $A R$.

DOI: 10.31725/0552-5829-2021-47-50

Одной из важных задач современных исследований в солнечной физике является поиск теоретических и наблюдательных признаков, определяющих способность активной области (АО) вызывать эрупцию вещества в высокие слои солнечной короны. В настоящее время существует уже достаточно много идей и моделей, объясняющих механизм возникновения эрупций в активных областях (AО) и последующих CME (coronal mass ejections). Среди них интересны модели, связанные со всплытием скрученных магнитных жгутов, с их длительным (сутки и более) существованием под магнитными аркадами в виде так называемых сигмоидов, а также с накоплением магнитной энергии в области магнитного шира, связанного с вращением пятен в АО и другими сдвиговыми движениями в фотосфере. «Стандартная модель вспышки», или CSHKP model [1-4], предполагает 
присутствие магнитных жгутов (MFR - magnetic flux ropes) в короне AO как предпосылку для инициирования эруптивных вспышек. MFR pacпознается как набор силовых линий магнитного поля, которые закручены вокруг своей центральной оси более одного раза [5]. Считается, что эти сложные структуры образуются в результате пересоединения потока по линии инверсии полярности (PIL) через фотосферный сдвиг и сходящиеся движения [6].

Цель данной работы - выяснить роль магнитных жгутов в возникновении вспышек и СМЕ на основе исследования предвспышечной динамики многоволновых излучений и восстановления коронального магнитного поля из фотосферы в корону (метод «NLFFF extrapolation») для ряда эруптивных (с CME) и неэруптивных (без CME, «confined») активных областей. Ранее для этих областей нами было обнаружено появление за несколько часов до вспышек класса М пересекающихся друг с другом ярких и "горя-

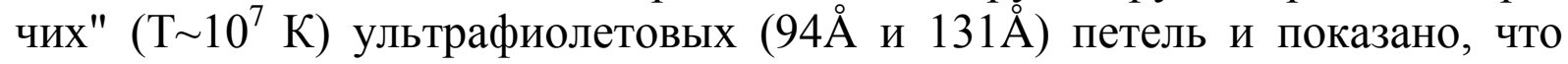
именно в месте их пересечения инициируется вспышка [7-10].

Для нелинейной бессиловой экстраполяции магнитных полей в корону АО мы воспользовались алгоритмами, приведенными в работах [11-13]. Анализ пространственной динамики микроволнового излучения активных областей выполнен на основе радиокарт Солнца, полученных на Радиогелиографе Нобеяма (NoRH) на частоте 17 ГГц с двумерным пространственным разрешением 10"-15", с временным интервалом между изображениями 10 минут, и на основе данных наблюдений SDO/AIA в крайнем ультрафиолетовом (КУФ) диапазоне $94 \AA$ и $131 \AA$ с пространственным разрешением 1.5", а также данных наблюдений фотосферного магнитного поля SDO/HMI. В данной работе приведены примеры экстраполяции магнитного поля в корону для двух АО: с эрупцией СМЕ и без эрупции вещества в корону.

AО 11402 наблюдалась на солнечном диске с 14.01.2012 по 27.01.2012, произвела 17 вспышек рентгеновского класса С, одну вспышку М и одну вспышку X, магнитная конфигурация эволюционировала от бета до бета-гамма. Мы исследовали вспышку M8.7 23 января 2012 (start 01:36, peak 03:50, end 06:06 UT, по данным NoRH), сопровождавшуюся CME.

На рис. 1 показана эволюция восстановленного магнитного поля АО 11402, КУФ (131 и и $94 \AA$ ) и радиоизлучения (17 ГГц) в круговой поляризации до и во время вспышки 23.01.2012. На верхней панели вблизи от большого пятна интенсивного магнитного поля виден магнитный жгут, охватывающий пятно слева. Ясно видно, что жгут расположен под силовыми линиям, исходящими из пятна, и перпендикулярен им. Его формирование началось за три часа до начала вспышки. Вспышка началась с уярчения (в КУФ, 131А) области вдоль магнитного жгута, затем уярчение распространилось вокруг пятна, образовав яркое кольцо (средняя панель). После этого произошло формирование и выброс яркой петлеообразной струк- 
туры (правая панель), которая, по-видимому, и дала начало СМЕ. Во время вспышки происходит изменение структуры радиоизлучения (нижняя панель, контуры в круговой поляризации), которое коррелирует пространственно со структурой уярчения в КУФ.

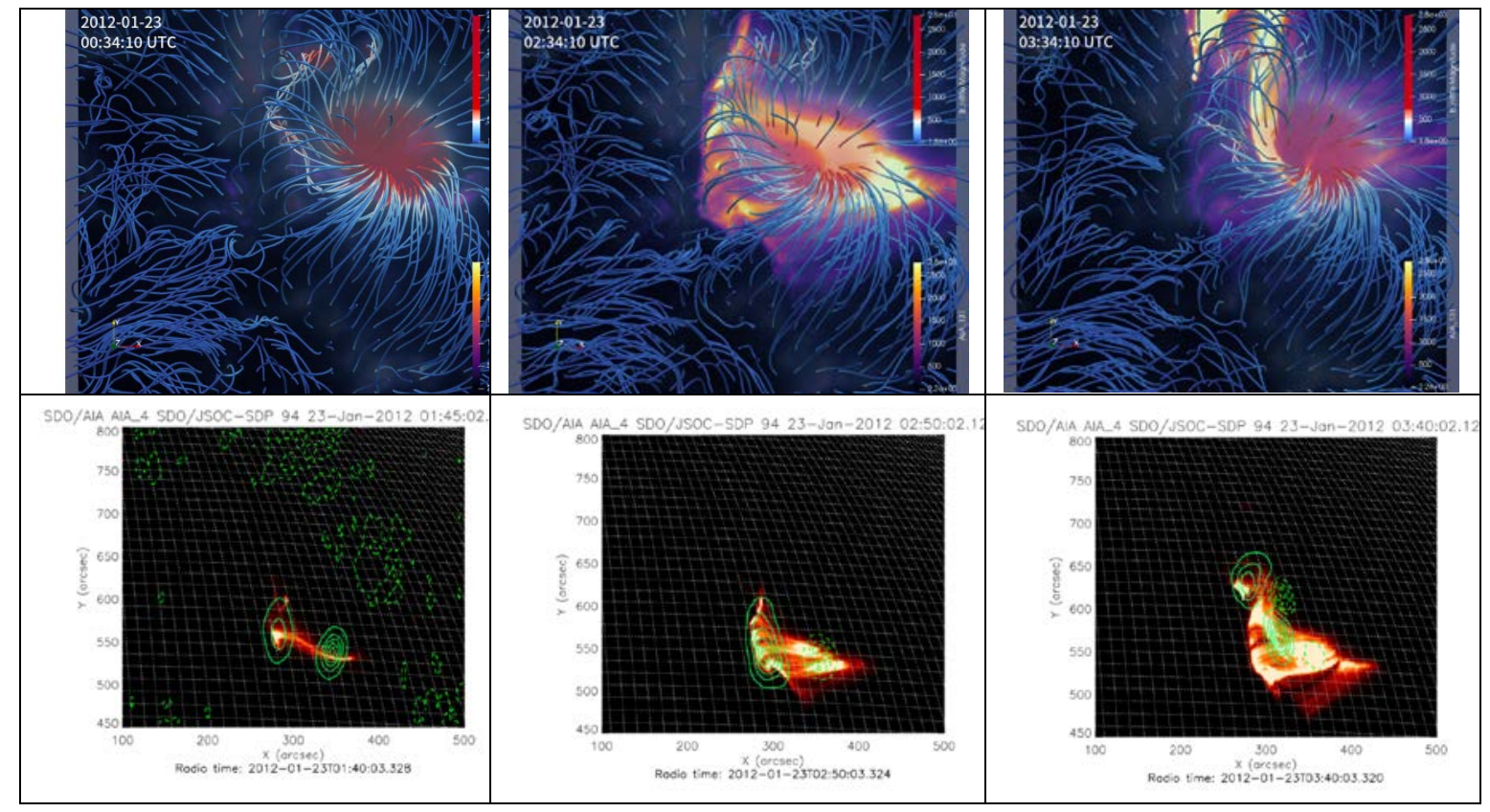

Рис. 1.

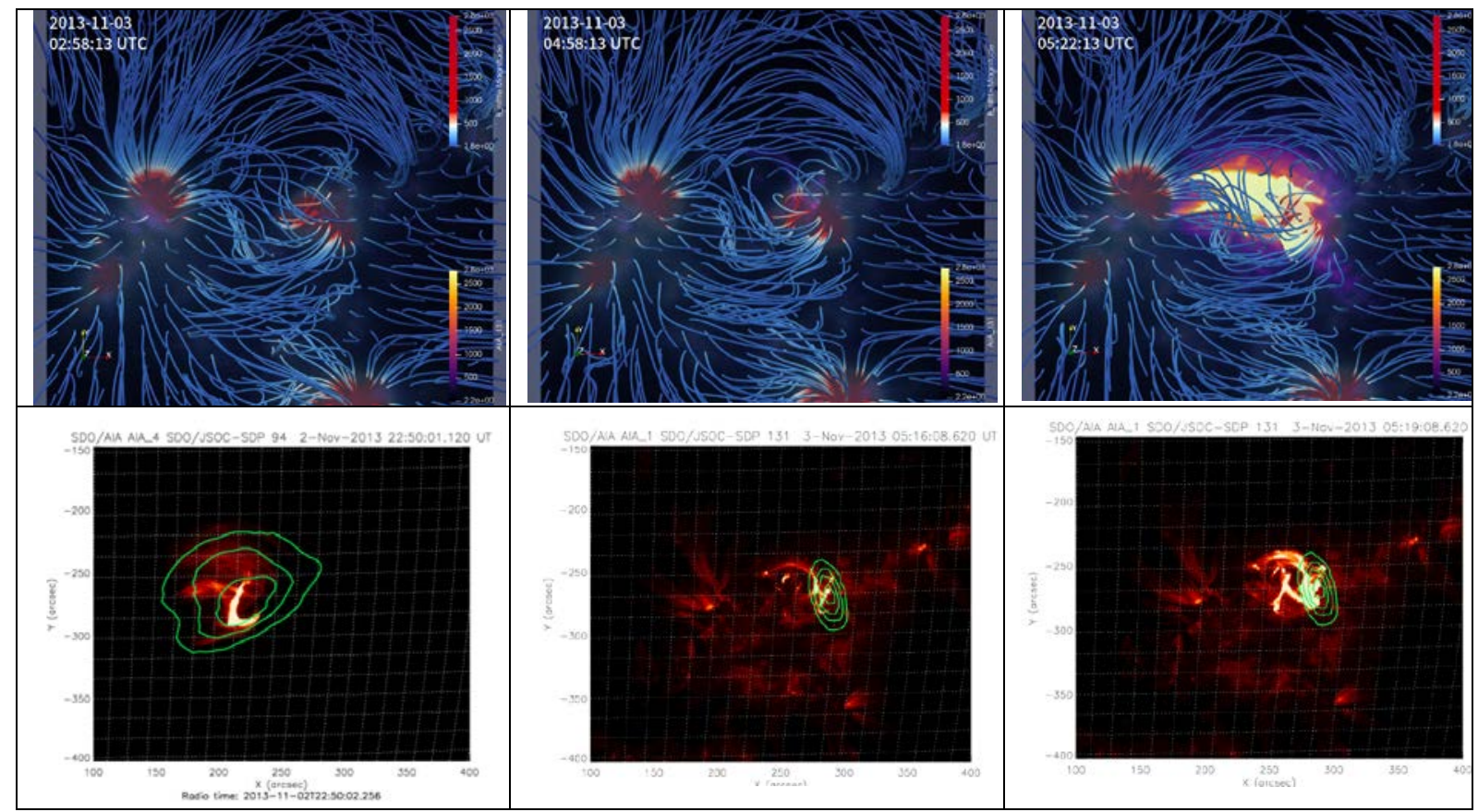

Рис. 2.

Активная область АО 11884 наблюдалась на солнечном диске с 26.10.2013 по 07.11.2013, произвела 13 вспышек рентгеновского класса С и 
три вспышки М, магнитная конфигурация эволюционировала от бетагамма-дельта до бета. АО производит всего одну вспышку М 4.93 ноября 2013 (start 05:19, peak 05:21, end 06:30 UT, по данным NoRH) без эрупции при магнитной конфигурации бета-гамма.

На рис. 2 показана эволюция магнитного поля в этой активной области, КУФ (131 и и $94 \AA)$ и радиоизлучения (17 ГГц) в интенсивности до и во время вспышки. На верхних панелях видно, что за 2-3 часа до вспышки между двумя соседними пятнами, соединенными магнитными арками силовых линий, прямо под ними и почти перпендикулярно к ним, сформировался мощный изогнутый жгут магнитного поля (левая и средняя панели). Именно здесь началась вспышка, проявившая себя в виде возгорания скрещенных КУФ петель (правая панель). На эту же область приходится максимум яркости радиоизлучения на 17 ГГц (нижняя панель).

В заключение отметим, что главным отличием между рассмотренными двумя активными областями было отличие в структуре магнитного поля над ними. В АО 11402 было одно большое пятно с сильным магнитным полем, что создавало открытую структуру магнитного поля на корональных высотах и, соответственно, обеспечивало легкий выход вспышечной плазмы и формирование СМЕ. В АО 11884, в отличие от АО 11402, присутствуют не одно, а четыре пятна с сильным магнитным полем. Вместе они создают мощную закрытую конфигурацию магнитного поля. Очевидно, именно наличие такой мощной закрытой структуры силовых линий над магнитным жгутом не позволило произвести выброс вспышечной плазмы высоко в корону.

Работа выполнена при поддержке гранта РФФИ-ЧНФ №20-52-26006.

\section{Литература}

1. Carmichael, H. // NASA Spec. Publ., 1964, 50, 451

2. Sturrock, P.A. // Nature, 1966, 211, 695

3. Hirayama, T. // Solar Phys., 1974, 34(2), 323

4. Kopp, R.A., Pneuman, G.W. // Solar Phys., 1976, 50, 85.

5. Gibson, S. E., Fan, Y., Török, T., \& Kliem, B. // SSRv, 2006, 124, 131

6. van Ballegooijen, A.A., \& Martens, P.C.H. // ApJ, 1989,343, 971

7. Bakunina, I.A., Melnikov V.F.// AApTr, 2019, 31, Issue 3, 251

8. Bakunina, I.A., Melnikov, V.F. \&Morgachev, A.S. // Astrophysics, 2020, 63, No. 2, 252

9. Bakunina I. A., Melnikov V., Morgachev A. S. // Geomag. and Aeronomy, 2020, 60, No. 7, 853

10. Bakunina, I.A., Melnikov, V.F., Abramov-Maximov V.E, Morgachev, A.S. // Geomag. and Aeronomy, 2021, 61, No. 8, in print

11. Wiegelmann T. // Solar Phys., 2004, 219, 87

12. Stupishin A., Magnetic Field Library // GitHub. - URL https://github.com/AlexeyStupishin/Magnetic-Field_Library

13. Anfinogentov S., GXBox_prep. // GitHub. - URL https://github.com/Sergey- Anfinogentov/GXBox_prep 